\title{
Outer-sphere Ligand to Ligand Charge Transfer of Metal Complexes
}

\section{Arnd Vogler* and Horst Kunkely}

Institut für Anorganische Chemie der Universität Regensburg, Universitätsstr. 31, D-8400 Regensburg, Federal Republic of Germany

The electronic spectra of the salts $\left[\mathrm{Ni}^{\prime \prime}(\mathrm{tim})\right]^{2+}\left[\mathrm{M}^{\prime \prime}(\mathrm{mnt})_{2}\right]^{2-}(\mathrm{tim}=2,3,9,10$-tetramethyl-1,4,8,11-tetra-azacyclotetradeca-1,3,8,10-tetraene, $\mathrm{H}_{2} \mathrm{mnt}=1,2$-dicyano-1,2-ethylenedithiol, $\mathrm{M}^{2+}=\mathrm{Ni}^{2+}, \mathrm{Pd}^{2+}, \mathrm{Pt}^{2+}$ ) are dominated by an intense absorption band which is assigned to an outer-sphere ligand to ligand charge transfer transition from the complex anion to the cation.

Intramolecular (inner-sphere) charge transfer (CT) transitions play an important role in the photophysics and photochemistry of transition metal complexes. ${ }^{1}$ Optical CT may take place from the ligand to the metal (CTLM) ${ }^{2}$ from the metal to the ligand (CTML), ${ }^{2}$ from one metal to another metal (CTMM), ${ }^{2}$ or from one ligand to another ligand (CTLL) ${ }^{3-7}$ In principle it should be possible to observe all these optical CT transitions also as outer-sphere processes. Although intermolecular CT excitation of metal complexes becomes increasingly important in inorganic photochemistry ${ }^{8}$ only outer-sphere CTMM transitions are known. ${ }^{2}$ We report here our observation of an outer-sphere CTLL transition.

Intense absorption bands which are assigned to intramolecular CTLL transitions appear in the electronic spectra of square planar complexes which contain a 1,2-ethylenedithiolate ligand as electron donor and a 1,2-diimine ligand as electron acceptor. ${ }^{3,5}$ If the diimine and the dithiolate are co-ordinated in separate complexes which form an ion pair or a salt it might be possible to observe outer-sphere CTLL absorption bands. In order to explore this possibility we selected the yellow cation $[\mathrm{Ni}(\mathrm{tim})]^{2+9}(\mathrm{tim}=2,3,9,10-$ tetramethyl-1,4,8,11-tetra-azacyclotetradeca-1,3,8,10-tetraene) with two diimine units as electron acceptors. The anions $\left[\mathrm{M}(\mathrm{mnt})_{2}\right]^{2-10}\left(\mathrm{H}_{2} \mathrm{mnt}=1\right.$,2-dicyano-1,2-ethylenedithiol, $\left.\mathrm{M}^{2+}=\mathrm{Ni}^{2+}, \mathrm{Pd}^{2+}, \mathrm{Pt}^{2+}\right)$ served as electron donors.

Upon mixing acetone solutions of $[\mathrm{Ni}(\mathrm{tim})]\left(\mathrm{PF}_{6}\right)_{2}{ }^{9}$ and $\left[\mathrm{NEt}_{4}\right]_{2}\left[\mathrm{M}(\mathrm{mnt})_{2}\right]^{10}$ insoluble black substances with the analy-
$[\mathrm{Ni}(\mathrm{tim})]^{2+}$

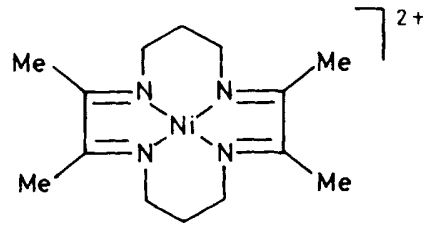<smiles>N#CC1=C(C#N)SC2(S1)SC(C#N)=C(C#N)S2</smiles>

$\left[M(m n t)_{2}\right]^{2-}$ 


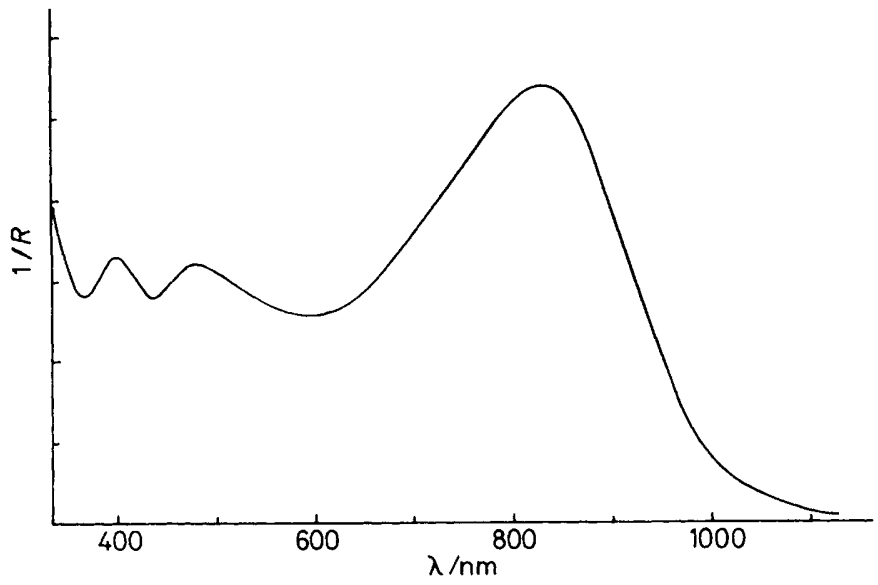

Figure 1. Reflectance spectrum of $[\mathrm{Ni}(\mathrm{tim})]\left[\mathrm{Ni}(\mathrm{mnt})_{2}\right] ; 1 / R(R=$ reflectance) in arbitrary units.

tical composition $[\mathrm{Ni}(\mathrm{tim})]\left[\mathrm{M}(\mathrm{mnt})_{2}\right]$ precipitated. The black colour is caused essentially by a very broad and intense long-wavelength band: $\mathrm{M}=\mathrm{Ni}, \lambda_{\max } 840 \mathrm{~nm}, \varepsilon \approx 10^{4}$ $\mathrm{dm}^{3} \mathrm{~mol}^{-1} \mathrm{~cm}^{-1}$ (Figure 1); $\mathrm{Pd}, \lambda_{\text {max }}$ 834; $\mathrm{Pt}, \lambda_{\text {max }}$. 824. In the shorter-wavelength region the long-wavelength bands of the components appear: $[\mathrm{Ni}(\mathrm{tim})]^{2+}$ at $\lambda_{\max } 392 \mathrm{~nm}(\varepsilon 2300$ $\left.\mathrm{dm}^{3} \mathrm{~mol}^{-1} \mathrm{~cm}^{-1}\right)$ and $\left[\mathrm{M}(\mathrm{mnt})_{2}\right]^{2-}$ at $\lambda_{\max } 472$ (3560) for $\mathrm{M}=$ $\mathrm{Ni}$ (Figure 1), $\lambda_{\max .} 441$ (5700) for $\mathrm{Pd}$, and $\lambda_{\max } 458$ (4400) for $\mathrm{Pt}$. The extinction coefficient of the $840 \mathrm{~nm}$ band of [Ni(tim)]$\left[\mathrm{Ni}(\mathrm{mnt})_{2}\right.$ ] was estimated by comparing its intensity of reflectance (Figure 1) with that of the shorter-wavelength bands of the components. Their extinction coefficients were determined in solution.

The intense absorptions of the salts $[\mathrm{Ni}(\mathrm{tim})]\left[\mathrm{M}(\mathrm{mnt})_{2}\right]$ at about $830 \mathrm{~nm}$ are assigned to an outer-sphere CTLL transition from the electron donor $\mathrm{mnt}^{2-}$ to the acceptor tim. This assignment is supported by the following considerations. The long-wavelength bands do not appear in the spectra of the separate complexes and their energy is almost independent of the metal of the complex anion. The direct participation of the co-ordinated tim ligand in the CTLL transition is also confirmed by the electronic spectra of the insoluble salts $[\mathrm{Ni}($ cyclam $)]\left[\mathrm{M}(\mathrm{mnt})_{2}\right]$ (cyclam $=1,4,8,11$-tetra-azacyclotetradecane). The cyclam ligand is related to tim but it is saturated and does not contain diimine units. Cyclam can thus not serve as electron acceptor. Consequently, the spectra of $[\mathrm{Ni}(\mathrm{cyclam})]\left[\mathrm{M}(\mathrm{mnt})_{2}\right]$ consist essentially of a superimposition of the spectra of the components $[\mathrm{Ni}(\text { cyclam })]^{2+11}$ $\left(\lambda_{\text {max. }}=450 \mathrm{~nm}\right)$ and $\left[\mathrm{M}(\mathrm{mnt})_{2}\right]^{2-}$.

This work was supported by the Stiftung Volkswagenwerk and the Fonds der Chemischen Industrie. We thank Dr. G. Herzog for measurements of reflectance spectra.

Received, 21st July 1986; Com. 1021

\section{References}

1 The state of the art of inorganic photochemistry has recently been reviewed in a special issue of $J$. Chem. $E d$., 1983, Issue 10, p. 57.

2 A. B. P. Lever, in 'Inorganic Electronic Spectroscopy,' Elsevier, Amsterdam, 1984.

3 A. Vogler and H. Kunkely, J. Am. Chem. Soc., 1981, 103, 1559, and references cited therein.

4 G. A. Heath, L. J. Yellowlees, and P. S. Braterman, Chem. Phys. Lett., 1982, 92, 646.

5 A. Vogler, H. Kunkely, J. Hlavatsch, and A. Merz, Inorg. Chem., $1984,23,506$.

6 G. A. Crosby, R. G. Highland, and K. A. Truesdell, Coord. Chem. Rev., 1985, 64, 41.

7 M. Haga, E. S. Dodsworth, and A. B. P. Lever, Inorg. Chem., $1986,25,447$.

8 V. Balzani, N. Sabbatini, and F. Scandola, Chem. Rev., 1986, 86, 319.

9 A. M. Tail and D. H. Busch, Inorg. Synth., 1978, 18, 22.

10 E. Billig, R. Williams, I. Bernal, J. H. Waters, and H. B. Gray, Inorg. Chem., 1964, 3, 663.

11 B. Bosnich, M. L. Tobe, and G. A. Webb, Inorg. Chem., 1965, 4, 1109. 